\title{
The Evolutionary Biology of Education: How Our Hunter-Gatherer Educative Instincts Could Form the Basis for Education Today
}

\author{
Peter Gray
}

Published online: 26 January 2011

(C) Springer Science+Business Media, LLC 2011

\begin{abstract}
Education is broadly defined as the set of processes by which each generation of human beings acquires the culture in which they grow up. By this definition, education is part and parcel of our biological makeup. An analysis of education in hunter-gatherer bands indicates that young humans are designed, by natural selection, to acquire the culture through their self-directed play and exploration. Research at a modern-day democratic school designed to facilitate self-education demonstrates that our hunter-gatherer educative instincts are quite adequate for education today, given an appropriate educational environment. The ideal environment for such education - found both in hunter-gatherer bands and at the school studied - is one in which young people (a) have unlimited free time and much space in which to play and explore; (b) can mix freely with other children of all ages; (c) have access to a variety of knowledgeable and caring adults; (d) have access to culturally relevant tools and equipment and are free to play and explore with those items; (e) are free to express and debate any ideas that they wish to express and debate; (f) are free from bullying (which includes freedom from being ordered around arbitrarily by adults); and (g) have a true voice in the group's decision-making process. The per-student cost required to create such settings is less than half that of the average for our current public schools.
\end{abstract}

P. Gray

Department of Psychology, Boston College

Chestnut Hill, MA 02467, USA

P. Gray $(\bowtie)$

340 S. Quinsigamond Ave.

Shrewsbury, MA 01545, USA

e-mail: grayp@bc.edu
Keywords Education · Evolution · Hunter-gatherers · Play · Children $\cdot$ Cultural transmission $\cdot$ Self-directed learning

Most of us when we hear the term education automatically think of schooling. For this article, I ask you to keep these two terms and concepts distinct. Schooling is a relatively new cultural innovation. It is the deliberate provision, by adults, of special settings and procedures designed to teach specific skills, beliefs, and concepts to the young. Education, in contrast, is far from new; it is older than our species. As applied to our species, it is the entire set of processes by which each new generation of human beings, in any cultural group, acquires the skills, knowledge, rituals, beliefs, lore, and values - in short, the culture - of the previous generation. To say that we are the supremely cultural animal is to say that we are the supremely educative animal.

Beginning well over a million years ago, we (our human genetic line) began moving along an evolutionary track that made us ever more dependent on cultural transmission, that is, upon education. Over time, we developed means of hunting, gathering, processing foods, protecting ourselves from predators, birthing, caring for infants, and combating diseases that depended increasingly on detailed, learned knowledge and theories about our local environment and on well-honed skills, including the crafting and using of tools, that were passed along from generation to generation. We also came to depend on increasingly high levels of cooperation within bands and across networks of bands, which required the cultural transmission of social mores, rules, rituals, stories, and shared cultural beliefs and values, all serving to help promote cooperation.

In any human group, children who failed to acquire crucial aspects of the culture around them would be at a serious disadvantage for survival and reproduction. They 
would not know how to perform economically essential tasks, how to get along well with others within their culture, or how to attract a mate for reproduction. Natural selection, then, would strongly favor characteristics that promoted young people's abilities to acquire the culture. These characteristics are what I refer to as educative instincts. The analysis that I present here suggests that the human educative instincts have much more to do with learning than with teaching. They are, largely, the characteristics that lead young people, on their own initiatives, to observe, explore, and practice essential elements of the culture that surrounds them.

In this article, I begin by examining how education occurs in hunter-gatherer cultures. It is in those cultures that we see most clearly the power of the human educative instincts. Then I present evidence, from research at a school designed for self-education, that the same instincts that worked so well to promote hunter-gatherers' education can still work effectively today, in our culture, given appropriate conditions. Finally, I point out how our traditional schools make education difficult by removing the conditions that allow children's educative instincts to operate effectively.

\section{Education in Hunter-Gatherer Cultures}

Our educative instincts took their present shape during the hundreds of thousands of years of evolutionary history when our ancestors were all hunter-gatherers. As one pair of anthropologists put it, the hunter-gatherer way of life is the only stable way of life our species has ever known (Lee and DeVore 1968). By comparison, our post-huntergatherer existence has been very short and turbulent. The advent of agriculture, beginning roughly 10,000 years ago, set into motion an ever-accelerating rate of cultural change in how we humans live; but however we live, we continue to do so with the biological drives and capacities that were honed by natural selection during our hunter-gatherer days.

We can't go back in time to observe education in our pre-agricultural ancestors, but we can make reasonable inferences about that process by examining it in those groups of people, in various isolated parts of the world, who managed to survive as hunter-gatherers into modern times. Today, the pure hunting and gathering way of life is almost completely obliterated, wiped out by intrusions from modern civilizations. But as recently as the 1970 s, and to some degree even later, it was still possible for anthropologists to find and study hunter-gatherers who were nearly untouched by modern ways. To learn about education in hunter-gatherer cultures, I have studied the anthropological literature on children's lives in such cultures. To supplement that literature, I (along with graduate student Jonathan Ogas) identified ten prominent anthropologists who, among them, had studied seven different hunter-gatherer cultures on three different continents and questioned them extensively, with a written questionnaire, about their observations of children's lives in the cultures they observed.

For all of this work, I have focused exclusively on the variety of hunter-gatherer cultures that anthropologists refer to as immediate-return or egalitarian hunter-gatherers, or sometimes as band societies. These are cultures in which people live in small bands (typically of 20 to 50 persons, including children) that move from place to place within a large but circumscribed territory to follow the available game and vegetation. They have a highly egalitarian social structure, make decisions by consensus, own little property, share food and material goods within and even across bands, do not have means for long-term food preservation, have little occupational specialization except that based on gender, and reject violence as a legitimate means of solving problems (Kelly 1995). Among the cultures of this type that in one way or another were included in my study are the $J u$ / 'hoansi (also called the !Kung, of Africa's Kalahari Desert), Hazda (of Tanzanian rainforests), Mbuti (of Congo's Ituri Forest), $A k a$ (of rain forests in Central African Republic and Congo), Efé (of Congo's Ituri Forest), Batek (of Peninsular Malaysia), Agta (of Luzon, Philippines), Nayaka (of South India), Aché (of Eastern Paraguay), Parakana (of Brazil's Amazon basin), and Yiwara (of the Australian Desert).

I have ignored, for this study, the category of huntergatherer society referred to as delayed-return or nonegalitarian hunter-gatherers, typified by the Kwakiutl of the American northwest coast and the Ainu of Japan. These are relatively sedentary societies where people exploit a particular local resource for food (commonly fish). They are characterized by high population densities, food storage, resource ownership and defense, hierarchical social structures, inherited status, and relatively high rates of violence and acceptance of violence as legitimate. Archeological evidence suggests that these cultures are more recent than the egalitarian band cultures and are less likely to represent the predominant living conditions of our pre-agricultural ancestors (Kelly 1995). In line with the practice of some anthropologists, when I use the term hunter-gatherer, unmodified, I am referring specifically to the band, egalitarian variety.

Despite great differences in their geography and their specific ways of hunting and gathering, hunter-gatherer societies (of the band type) are remarkably similar to one another in their basic social structure, social mores, and approach to education. Such similarity, across continents, adds confidence to the view that these societies represent reasonably well the kinds of hunter-gatherer societies that preceded the advent of agriculture. The research literature 
and our survey concerning children's lives in huntergatherer cultures reveal a remarkably consistent story, from culture to culture. Here are four conclusions that appear to apply to all hunter-gatherer cultures (of the band type) that have been studied (for more details, see Gray 2009a):

1. Hunter-gatherer children had to learn an enormous amount to become effective adults.

It would be a mistake to assume that because huntergatherer cultures were "simpler" than modern cultures, children had less to learn. The hunting-and-gathering way of life was highly knowledge-intensive and skill-intensive, and because of the absence of occupational specialization, each child had to acquire the whole culture, or at least that part of it appropriate to his or her gender.

To become hunters, boys - and girls, too, in those cultures where women as well as men hunted-had to learn how to identify and track the many dozens of different species of birds and mammals that their group hunted. They had to learn how to craft to perfection the tools of hunting, such as bows and arrows, blowguns and darts, snares, nets, and so on. And, of course, they had to develop great skill at using those tools. To become gatherers, girls - and boys also, to the degree that men also gathered-had to learn which of the countless varieties of roots, nuts, seeds, fruits, and greens in their area were edible and nutritious; when and where to find them; how to extract the edible portions; and how to process them. In addition, hunter-gatherer children had to learn to build huts, make fires, cook, fend off predators, predict weather changes, navigate their hunting and gathering grounds, treat wounds and diseases, assist births, care for infants, maintain harmony in the group, negotiate with neighboring groups, tell stories, make music, and engage in the various dances and rituals of their culture.

2. Hunter-gatherer adults did not direct children's education or in other ways tell them what to do. Children and even adolescents were free to play and explore, on their own, in their own chosen ways, "from dawn to dusk."

In the words of hunter-gatherer expert Richard Lee (1988, p. 264), hunter-gatherers were "fiercely egalitarian." They eschewed any attempts by one person to control the behavior of others. They had no chiefs or "big men"; they made all decisions within the band through debate until consensus was reached. Such egalitarianism was necessarily coupled with extraordinary personal autonomy. Huntergatherers did not tell one another what to do. Each person was free at any time to leave the band and join another band, and would do so if he or she felt put-upon. People were always free, on any given day, to join or not join a hunting or gathering party. If they joined, it was because they wanted to, not because they were compelled to. Food was shared, and they would get the same portion regardless of whether or not they had taken part in getting the food.

Remarkably, these principles of equality and autonomy were applied as much to children as to adults. Adults did not tell children what to do any more than they told other adults what to do; they believed that children's own wills should be their guides. Here is a sample of quotations, from various researchers and observers of hunter-gatherers, that reinforce this point (Gray 2009a):

- "Aborigine children [of Australia] are indulged to an extreme degree, and sometimes continue to suckle until they are four or five years old. Physical punishment for a child is almost unheard of" (Gould 1969, p. 90).

- "Hunter-gatherers do not give orders to their children; for example, no adult announces bedtime. At night, children remain around adults until they feel tired and fall asleep.... Parakana adults [of Brazil] do not interfere with their children's lives. They never beat, scold, or behave aggressively with them, physically or verbally, nor do they offer praise or keep track of their development.... Children do not go to parents for help or to complain about one another... Adults do not give any indication of being worried about the psychological future of their children. Whether or not their children will become effective adults is not an issue" (Gosso et al. 2005, pp. 218, 226).

- "The idea that this is 'my child' or 'your child' does not exist [among the Yequana, of Venezuela]. Deciding what another person should do, no matter what his age, is outside the Yequana vocabulary of behaviors. There is great interest in what everyone does, but no impulse to influence-let alone coerce - anyone. The child's will is his motive force" (Liedloff 1977, p. 90).

- "Infants and young children [among Inuit huntergatherers of the Hudson Bay area] are allowed to explore their environments to the limits of their physical capabilities and with minimal interference from adults. Thus if a child picks up a hazardous object, parents generally leave it to explore the dangers on its own. The child is presumed to know what it is doing" (Guemple 1988, p 137).

- "Ju/'hoan children [of Africa's Kalahari Desert] very rarely cried, probably because they had little to cry about. No child was ever yelled at or slapped or physically punished, and few were even scolded. Most never heard a discouraging word until they were approaching adolescence, and even then the reprimand, if it really was a reprimand, was delivered in a soft voice" (Thomas 2006, p 198).

To her description of Ju/'hoan child-raising practices, Thomas (2006, pp. 198-199) adds: "We are sometimes told that children who are treated so kindly become spoiled, but 
this is because those who hold that opinion have no idea how successful such measures can be. Free from frustration or anxiety, sunny and cooperative, and usually without close siblings as competitors, the children were every parent's dream. No culture can ever have raised better, more intelligent, more likable, more confident children." [Thomas's statement about the lack of close siblings as competitors refers to the fact that births for hunter-gatherer women are usually spaced at least four years apart. The continuous, on-demand nursing of children until they are three or four years old apparently produces a hormonal effect that delays ovulation in women who are lean, as hunter-gatherer women are, and serves as a natural means of birth control.]

Hunter-gatherer children generally stay within eyeshot or at least hearing distance of their mothers or other adults until they are about four years old, at which age they begin to prefer the company of other children and begin to run freely with other kids. In our survey, we asked the ten anthropologists how much time children in the culture they observed were free to play each day, and the answer we received from all of them was essentially this: "They were free to play almost all of the time, from dawn to dusk." Here are three typical responses (Gray 2009a):

- "Both girls and boys had almost all day every day free to play" (Alan Brainard, concerning the Nharo, of southern Africa).

- "Children were free to play nearly all the time; no one expected children to do serious work until they were in their late teens" (Karen Endicott, concerning the Batek of Malaysia).

- "Boys were free to play nearly all the time until age 1517; for girls most of the day, in between a few errands and some babysitting, was spent in play" (Robert Bailey, concerning the Efé, of central Africa).

These comments are consistent with published reports. In a formal study of Ju/'hoan children's activities, Patricia Draper (1976, pp. 210, 213) concluded: "Girls are around 14 years old before they begin regular food gathering and water- and wood-collecting. This is in spite of the fact that they may be married before this age. Boys are 16 years old or over before they begin serious hunting....Children do amazingly little work." The Hazda (of the Tanzanian rainforests in Africa) are sometimes cited as an exception to the rule that huntergatherer children engage in little productive work. Hazda children forage for a good portion of their own food. But a study of Hazda children, aged 5 to 15 , revealed that they spent only about two hours per day foraging, in the rich vegetative areas near camp, and that even while foraging they continued to play (Blurton Jones et al. 1994).

A number of researchers have compared the childraising practices of hunter-gatherers with those of agrarian (farming) communities. While hunter-gatherer parents are indulgent and permissive, agrarian parents are typically strict and autocratic (Barry et al. 1959). While huntergatherers value their children's willfulness and independence, agrarian parents value obedience. While huntergatherer children are free to play and explore all day on their own, agrarian children are required to work a good portion, if not most of the day, at chores in the home and field. A study of peoples in Botswana with mixed huntergatherer and agrarian subsistence revealed that the more a family was involved in hunting and gathering and the less they were involved in farming, the more time children had to play (Bock and Johnson 2004).

Researchers have offered a variety of interrelated explanations of the differences between hunter-gatherers and farmers in child-raising practices. Perhaps the most obvious explanation has to do with the immediate economic benefits, or lack of such benefits, gained from children's work. Hunting and gathering are knowledge- and skillintensive, but not labor-intensive. The adults hunt and gather with a sense of play, and they have plenty of time left over for such leisure activities as gossiping, visiting friends in neighboring bands, making music, and in other ways playing (Gray 2009a; Sahlins 1972). Moreover, the birth rate among hunter-gatherers is relatively low, so there are relatively few young mouths to feed. Hunter-gatherers simply don't need child labor. In contrast, farming is highly labor-intensive, and much of that labor is unskilled and can be done by children. Farmers typically have more children than do hunter-gatherers, and to feed and care for them all the children must work.

Other explanations, quite closely related to this immediate economic one, focus on the values imparted by the different methods of child rearing and on parents' goals in child raising (Barry et al. 1959; DeVore et al. 1968). The social and economic life of adult hunter-gatherers requires assertiveness, creativity, and individual judgment. To have influence in a society where decisions are made by debate and consensus, you must be assertive. Hunting and gathering themselves require creative, diverse methods and on-the-spot judgments to meet the unpredictable, ever-changing conditions of nature. As Whiting (in DeVore et al. 1968) has pointed out, the permissive parenting style of hunter-gatherers seems ideally designed to promote assertiveness, creativity, and independence. In contrast, most agrarian societies have a stratified, hierarchical social structure, with landowners at the top, where obedience to lords and masters may be essential to survival. Moreover, farming itself depends more on adherence to tried and true routines than on individual creativity. It is no wonder, then, that farming parents should be motivated to beat the willfulness out of their children and train them in lessons of conformity and obedience. 
When hunter-gatherer adults were asked about their child-raising practices, they talked about each person's right to make their own decisions, but they also pointed out that young people learned through their freely chosen activities and would begin to contribute to the band's economy, on their own free will, when they were ready to do so. Their view of education seems well summed up by a Ju/'hoan folk expression that can be translated roughly as "Children teach themselves" (Bakeman et al. 1990).

3. Hunter-gatherer children acquired the skills of their culture, and consolidated their knowledge, by playing at culturally valued activities.

Hunter-gatherer children were never isolated from the activities of adults in the band. They observed all that went on and they heard the gossip, stories, and debates of adults. They incorporated all this into their play, not because any adult told them to but because they were naturally motivated to.

In response to our survey question about what the children played at, we received many answers that showed that children played at activities that were of economic or social value in their culture (Gray 2009a). Digging up tubers, fishing, smoking porcupines out of holes, cooking, caring for infants, climbing trees, building vine ladders, building huts, using knives and other tools, making tools, carrying heavy loads, building rafts, making fires, defending against attacks from make-believe predators, imitating animals (a means of identifying animals and learning their habits), making music, dancing, storytelling, and arguing were all mentioned by one or more respondents. The specific lists differed from culture to culture, in accordance with differences in the skills that were exemplified by adults in each culture.

All of the respondents said that boys in the culture they studied engaged in a great deal of playful hunting. The two respondents who studied the Agta (of the Philippines) - a culture in which women as well as men regularly huntnoted that girls as well as boys in that culture engaged in much playful hunting. Young children, with little bows and arrows (or other weapons, depending on the culture), might in their play shoot at butterflies, toads, and rodents. Eventually, as they became skilled, they might in their play begin to kill some small animals and bring them home to cook. Over time, playful hunting gradually became real hunting, still in the spirit of play.

Collin Turnbull, who studied and wrote extensively about the Mbuti (of Africa's Ituri Forest), described how Mbuti children of both sexes (age 9 and up) practice the art of argument in their play. He wrote:

It may start through imitation of a real dispute the children witnessed in the main camp, perhaps the night before. They all take roles and imitate the adults. It is almost a form of judgment for if the adults talked their way out of the dispute the children having performed their imitation once, are likely to drop it. If the children detect any room for improvement, however, they will explore that, and if the adult argument was inept and everyone went to sleep that night in a bad temper, then the children try and show that they can do better, and if they cannot, then they revert to ridicule which they play out until they are all rolling on the ground in near hysterics. That happens to be the way many of the most potentially violent and dangerous disputes are settled in adult life. (Turnbull 1982, pp. 142-143)

Turnbull noted in his writings that Mbuti children would build a whole village of play huts, some distance away from their band's actual temporary village, and then use that as a playground to act out scenes they had witnessed among the adults or to improvise new ones. In her response to our survey, Nancy Howell reported the same observation concerning Ju/'hoan children. Apparently, hunter-gatherer children, in their play, spend a great deal of time practicing the arts and crafts of adulthood.

4. Hunter-gatherer children and adolescents played and explored together in age-mixed groups.

The play of hunter-gatherer children occurred almost always in age-mixed groups. A typical group playing together at any given time might consist of half a dozen children ranging in age from 4 to 11 , or from 7 to 15 . Even if hunter-gatherer children wanted to segregate by age, they would rarely find more than one or two playmates within a year or two of their own age. Because hunter-gatherer bands were relatively small and births were widely spaced, the number of potential playmates for any given child was limited. As Patricia Draper put it, in her response to our survey: "Any child with enough motor and cognitive maturity could enter into any game. Older teenagers and adults could and did play as well, though not for as long or with the same enthusiasm as the children." I will return later to the issue of age mixing. I think it plays a huge role in children's natural means of education.

\section{Education at a Modern Democratic School Designed for Self-Education}

At this point you might be thinking: "Well, that system of education may have been fine for hunter-gatherers, but we are not hunter-gatherers. The educational needs of our children today are very different." Indeed, our children's educational needs are in some ways quite different from those of hunter-gatherers. For starters, we have reading, writing, and arithmetic - skills that were foreign to hunter- 
gatherer cultures. Some educational researchers, including at least one who brings an evolutionary perspective to his work (Geary 2008), have argued that children's natural ways of learning are inadequate for learning the three R's and that is one reason why school-imposed drill is essential. I might agree were it not for my observations and research at a remarkable alternative school, the Sudbury Valley School, located in Framingham, Massachusetts.

Sudbury Valley defies the usual conceptions of what a school must be in our modern era. Here is a brief description. The school admits students from age 4 on through high school age, on a first-come first-served basis, with no attention to measures of ability. It is a private day school, but it operates on a per-pupil budget less than half that of the local public schools. In recent years, the school has generally had between 140 and 200 enrolled students and nine or ten adult staff members. The school is governed by the School Meeting, which makes all school rules, at which each student and staff member has one vote. The school has no curriculum, gives no tests, does not monitor students' progress, and does not assign students to classes or special spaces. All students, regardless of age, are allowed - all day long, day after day - to go wherever they wish in the school's two buildings and ten-acre campus, to associate with whom they please, and to do whatever they wish as long as it does not violate any of the school's democratically legislated rules (which serve to protect the school community and the rights of individuals).

What the school does provide is access to tools of learning. There are computers, books, a woodworking shop, a fully equipped kitchen, a pond, a nearby woods, athletic equipment, and adult staff members with expertise in a wide variety of endeavors who provide help and instruction when asked. The students have access to all of this, but they are never required or coaxed to take advantage of any of these resources. Just as is true of hunter-gatherer children and adolescents, they are free to play and explore on their own, all day, every day, and that is what they do. The staff at the school-and the parents who send their children there-believe, as hunter-gatherers did, that children who are allowed to play and explore freely will learn what they need to know to become effective adults.

The school has been operating in this way for 43 years. It has hundreds of graduates, including many who did all of their primary and secondary schooling there. Follow-up studiesincluding one that I conducted many years ago - show that the graduates have done very well in life (Gray and Chanoff 1986; Greenberg and Sadofsky 1992; Greenberg et al. 2005). Those who have wanted to go to college - a group that constitutes the majority of the graduates - have had no difficulty getting into good colleges and doing well there, and others have pursued good careers (in such areas as arts, skilled crafts, information technology, and business startups) that do not require college. Collectively, the graduates occupy the whole range of professions that we value in our society. The great majority of them report no regrets at all about attending such an unusual school; they feel that the school gave them many advantages. Relatively recently, a worldwide Sudbury school movement has been spreading. Today, worldwide, there are roughly 40 schools explicitly modeled after Sudbury Valley (a list can be found at the Sudbury Valley School website).

How do students learn at this school? Research that my university students and I have conducted indicates that they learn in very much the same ways that huntergatherer children learn (Gray 2007). They explore and play, in age-mixed groups as well as alone, at activities that are valued in the culture around them, with tools that are crucial to the culture. Whereas hunter-gatherer children played with bows and arrows, digging sticks, and vine ladders, Sudbury Valley students play at computers and at games that involve the written word and numbers. They explore not just by examining the immediate physical and social world around them but also by reading about the subjects that interest them and by asking questions of staff members and other students. Sometimes, a group of students will ask a staff member to lead a course or regular discussion group on a topic of their interest. In this environment, no bell tells them to stop pursuing a passionate interest; they can delve as deeply as they like, for as long as they like, into any subject that they like. In the process, they develop the basic skills and the passionate specific interests that lead, eventually, to a career decision.

Another pool of children and adolescents learning on their own in our society are those involved in the rapidly growing "unschooling" movement (Kirschner 2008). These are young people who don't attend school at all. They are usually officially registered as homeschoolers, but in fact are not subjected to any curriculum or tests at home because their parents subscribe to the philosophy that children learn best when they pursue their own interests in their own chosen ways. I have recently collected many stories from unschooling parents about how their children learned to read and to calculate with numbers, and collectively, those stories make a case very similar to that resulting from our studies at Sudbury Valley (for an analysis of the stories, see Gray 2010a, d). Children on their own initiative, in a literate and numerate culture, naturally play with words and numbers and thereby become readers, writers, and proficient enough with math to meet the demands of life in our culture. Sudbury Valley children and unschooled children do not develop the fear and loathing of math that is so common elsewhere in our culture, so if they choose to study math formally-for example, to prepare to take the math SAT or ACT for college admission - they learn quickly, eagerly, and effi- 
ciently. As is true of people in the larger culture, a few enjoy numerical and abstract symbol play so much that they go on to become mathematicians, and a few others enjoy words so much that they become writers.

\section{The Educative Instincts: Play and Exploration}

In 1898, just 39 years after Darwin's On the Origin of Species appeared, the German philosopher and naturalist Karl Groos published a book entitled The Play of Animals in which he applied Darwin's theory to an analysis of animal play. Like Darwin, Groos had a sophisticated, modern understanding of the relationship between instinct and learning. He recognized that learning is not something that is superimposed upon instinct, but that it itself arises out of instinct and serves, among other things, to modify and refine instinctive behavior patterns to suit present conditions. Groos's central argument, in The Play of Animals, was that mammals come into the world with instincts to play at the vary activities that they most need to develop in order to become effective adults. Predators play at preying; prey animals play at dodging and darting and getting away; monkeys play at swinging from branch to branch in trees; males of most species play at fighting; and so on. Groos's book has had a great impact on modern animal behavior research. It has inspired much research into the functions of animal play, and its thesis, with some refinements and qualifications, is generally accepted today by biologists who study animal play.

Three years after the appearance of The Play of Animals, Groos (1901) published a second book, The Play of Man, in which he extended his theory of animal play to humans. Groos recognized that a basic difference between humans and other mammals lies in our extraordinary dependence on culture. He recognized that our survival depends on our abilities, when young, to acquire the skills and knowledge unique to the culture in which we are born. So, according to Groos, natural selection enlarged the play drive in humans and shaped it in a manner to include a strong element of mimicry. Human children play not just at species-specific skills (the kinds of skills that characterize the species everywhere), like other mammals do, but also play at culture-specific skills. According to Groos, children come into the world with an innate drive to look around and see what the adults, especially the most admired and successful adults, are doing and to incorporate those activities into their play.

Unlike his book on animal play, Groos's book on human play is little read today and rarely cited. In fact, it has been allowed to go out of print. My research suggests, however, that Groos's The Play of Man contains insights that should be understood by every educator today. In fact, my main criticism of Groos's work on human play is that he didn't go far enough. He did not conceive of the idea that the human instincts to acquire the culture around them are so powerful that, given appropriate environmental conditions, they can provide the primary foundation for education even in our modern world.

In addition to play, the other powerful force for children's self-education is curiosity. Groos considered exploration (motivated by curiosity) to be a category of play, but most play researchers today consider the two to be distinct (Power 2000). Learning can be divided at least roughly into two broad categories - learning to do (skill learning) and learning about (information learning). Play serves primarily the former, and exploration serves primarily the latter. Stated differently, exploration provides information and play provides practice.

Just as the play drive has expanded in our species to serve the function of cultural acquisition, so apparently has curiosity. Children and adolescents (and adults too) everywhere, when free, show extraordinary curiosity about the world around them, especially the social and cultural world. That is why gossip is a central activity to every human culture. It also explains why children pay special attention to the activities and conversations of older children and adults and why, when free to do so, they ask never-ending questions about what is going on. Given its extraordinary importance, psychologists have paid far too little research attention to human curiosity.

\section{Conditions that Maximize the Power of the Educative Instincts}

Because our instincts for self-education were shaped by natural selection during the long period when we were all hunter-gatherers, we might expect those instincts to function best in the context of a hunter-gatherer band or a modern setting that replicates essential aspects of such a band. The founders of the Sudbury Valley School did not set out to model a hunter-gatherer band. Their aim was to create a school in line with the fundamental tenets of American democracy (Sudbury Valley School 1970). But, to my eyes, the school contains precisely those elements of a huntergatherer band that are most essential for children's selfeducative instincts to operate well. Perhaps this is no coincidence. It can be argued that hunter-gatherer societies were the original democracies (Ingold 1999). Here, I offer a list of what seem to me to be the most crucial conditions for children's education - conditions that exist both in huntergatherer bands and at the Sudbury Valley School (also presented in Gray 2008b).

Time and Space for Play and Exploration

Self-education through play and exploration requires enormous amounts of unscheduled time-time to do 
whatever one wants to do, without pressure, judgment, or intrusion from authority figures. That time is needed to make friends, play with ideas and materials, experience and overcome boredom, and develop passions. In huntergatherer bands, adults place few demands on children and adolescents, partly because they recognize that young people need to explore and play on their own to become competent adults. The same is true at Sudbury Valley.

Self-education also requires space-space to roam, to get away, to explore. That space should, ideally, encompass the full range of terrains relevant to the culture in which one is developing. Hunter-gatherer adults trust their children to use good judgment in deciding how far they should venture away from others into possibly dangerous areas. At Sudbury Valley, children are likewise trusted, within the limits set by prudence in our modern, litigious society. They can explore the surrounding woods, fields, and nearby stream, and by signing out to let others know where they are going, those who have reached a criterion age can venture as far off campus as they choose.

\section{Free Age Mixing Among Children}

As I noted earlier, hunter-gatherer children necessarily play in age-mixed groups as there are not enough children of any given age for age-segregated play. At Sudbury Valley, there are enough children that they could play just with others close in age, but they don't. In quantitative studies, we have observed that children commonly, of their own choice, play across large age ranges - often of four years' difference or more (Gray and Feldman 1997). Much of my own and my university students' research at Sudbury Valley has focused on the educative value of age mixing (Feldman and Gray 1999; Gray and Feldman 2004). We have described evidence that age-mixed play is qualitatively different from same-age play. It is less competitive, more nurturing, and offers unique learning opportunities both for the older and younger participants.

Age mixing allows younger children to play at and learn from activities that they could not do alone. As illustration, imagine two four-year-olds trying to play a simple game of catch (Gray 2008c). They can't do it. Neither can throw the ball straight enough for the other to catch it, and neither can catch well enough to snag the other's wild throws. In a world of just four-year-olds, there would be no catch. But a four-year-old and an eight-year-old can play catch and enjoy it. The older child can toss the ball gently into the hands of the four-year-old so he or she has a chance to catch it, and the older child can run and leap well enough to catch at least some of the younger child's wild throws. In a world of just four-year-olds, there is no catch, but in a world that includes eight-year-olds as well as four-yearolds, everyone has a chance to learn and enjoy this skilled game. The same applies to all sorts of activities that stretch the abilities of younger children, including reading. A common scene at Sudbury Valley is one in which a group of children - some of whom can read and some of whom cannot - are huddled around a computer screen or playing some other kind of game that involves reading. The older children read aloud the words that the younger ones cannot read - not deliberately to teach but just to keep the game going. The result is that the younger children pick up the words they see in front of them and hear pronounced, and soon they are in the initial stages of reading themselves.

Age mixing benefits the older children as well as the younger. In an age-mixed environment, all children have the opportunity to practice being mature - to practice leading, guiding, and caring for others-through their interactions with younger children. At Sudbury Valley, we have observed countless instances in which older children went out of their way to help much younger ones (Gray and Feldman 2004). The presence of younger children seems to draw out the nurturing instincts in children and adolescents of both sexes and to promote the development of nurturing behavior (for further evidence of this, see Ember 1973). We also observed many scenes in which older children explained concepts to younger ones - concepts such as rules of a game, rules of the school, the best way to find lost mittens, and the phonetic sounds of letters. As all teachers know from experience, explaining a concept to others is often the best way to stretch and consolidate one's own understanding of that concept. In an age-mixed environment, all children have the opportunity to learn through teaching.

Children learn from the presence of older and younger children even when they are not directly interacting across age. Older children provide models that younger ones try to emulate. At Sudbury Valley, young children become interested in reading not so much because they see adults reading but more because they see children a little older than themselves reading. Five-year-olds aren't particularly interested in emulating adults; adults are too far ahead of them, too much in a different world. But five-year-olds do very much want to be like the cool seven- and eight-yearolds that they see around them. If those seven- and eightyear-olds are reading and discussing books, or are playing computer games that require reading, then the five-yearolds want to do that too. The same applies to the whole realm of activities that occur at the school - tree climbing, cooking, playing musical instruments, and so on.

Just as younger children are attracted to the more sophisticated activities of older ones, older children are often attracted to the creative and imaginative activities of younger ones. At Sudbury Valley, we have frequently observed teenagers playing with paints, clay, or blocks, or playing make-believe games, often with younger children. 
These are activities that most teenagers elsewhere in our culture would have long since abandoned. Through such play, the teenagers become wonderful artists, builders, storytellers, and creative thinkers.

Comparable studies of age mixing in hunter-gatherer bands have not been conducted, but I suspect that all of the advantages of age-mixed play that we have observed at Sudbury Valley would occur in hunter-gatherer bands as well, though the specific activities practiced would be different.

\section{Access to Knowledgeable and Caring Adults}

In hunter-gatherer bands, the adult world is not segregated from the children's world. Children see what adults do and incorporate that into their play. They also hear the adults' stories, discussions, and debates, and they learn from what they hear. When they need adult help, or have questions that cannot be answered by other children, they can go to any of the adults in the band. All of the adults care for them. Most of the adults, in fact, are literally their aunts and uncles.

At Sudbury Valley, too, adults and children mingle freely, though the ratio of adults to children is much smaller there than in a hunter-gatherer band. There is no place in the school where staff members can go but students cannot. Students can listen into any adult discussions and observe whatever the adults are doing, and they can join in if they wish. Students who need help of any kind can go to any of the staff members. A child who needs a lap to sit on, or a shoulder to cry on, or personal advice, or the answer to some technical question that he hasn't been able to find on his own, or (occasionally) more prolonged help in the form of a tutorial or course, knows just which adult will best satisfy his or her need. The adults are not literally aunts and uncles, but they are much like aunts and uncles. They know all of the students over the entire span of time that they are students at the school (unlike teachers in a conventional school who know each set of students for just one year) and take pride in watching them develop. Since the staff members must be reelected each year by vote that includes all of the students in the school, they are necessarily people who like kids and are liked by kids.

Access to Equipment and Freedom to Play with that Equipment

To learn to use the tools of a culture, people need access to those tools. Hunter-gatherer children played with knives, digging sticks, bows and arrows, snares, musical instruments, dugout canoes, and all of the other items of equipment that were crucial to their culture. At Sudbury Valley, children have access to a wide range of the equipment that is of most general use to people in our culture, including computers, woodworking equipment, cooking equipment, art materials, sporting equipment of various types, and many walls filled with books.

\section{Free Exchange of Ideas}

Intellectual development occurs best in a setting where people can share ideas freely, without censorship or fear of being ostracized. According to anthropologists' reports, hunter-gatherers were non-dogmatic in their beliefs, even in their religious beliefs (Gray 2009a; Thomas 2006). People could say what they please, without fear, and ideas that had any consequence to the group were debated endlessly. The same is true at Sudbury Valley. The school has deliberately refrained from becoming aligned with any particular religious or political ideology. All ideas are on the table. In this kind of environment, an idea is something to think about and debate, not something to memorize and feed back on a test. Daniel Greenberg, the school's leading philosopher, has described the school as "a free marketplace of ideas" (Sudbury Valley School 1970). Children who may not hear much discussion of politics or religion at home hear it at school, and they hear every side of every issue.

\section{Freedom from Bullying}

To feel free to explore and play, a person must feel safe, free from harassment and bullying. Such freedom occurred to a remarkable extent in hunter-gatherer bands, and it does also at Sudbury Valley. According to anthropologists, the close-knit personal relationships, the age mixing, and the non-competitive, egalitarian ethos of hunter-gatherer cultures worked effectively to prevent serious bullying (Gray 2009a). If an older or bigger child seemed to be picking on a younger or smaller one, others would step in and quickly stop it. The same occurs at Sudbury Valley, and in addition, research at the school suggests that the simple presence of young children has a pacifying effect on older children (Gray and Feldman 2004). Moreover, at Sudbury Valley, the school's democratically created rules and judicial system, in which children of all ages are involved, prevent serious bullying. Students who feel harassed in any way can "bring up" the offender, to appear before the Judicial Committee, comprising school members of all ages. This contrasts sharply with the case in many conventional schools where bullying is a way of life (Gray 2010c, e). Students there who report bullying are snitches or tattletales, and teachers can often get away with bullying because they make the rules and are not subject to them. Because students make the rules at Sudbury Valley and have responsibility for enforcing them, they have far more 
respect for the rules than do students in a standard school who have little or no voice in rule creation or enforcement (for further elaboration, see Gray 2010c).

\section{Immersion in a Democratic Community}

Hunter-gatherer bands and the Sudbury Valley School are, in quite different ways, democracies. As I noted earlier, hunter-gatherer bands did not have chiefs who make decisions for the group. Instead, all group decisions were made through long discussions until all who cared came to an agreement. Anybody, including children, could take part in those discussions. Sudbury Valley is administered through a formal democratic process, involving discussions and votes of the School Meeting, where each student and staff member who chooses to attend has an equal vote. Immersion in the democratic process endows each person with a sense of responsibility that helps motivate education. If my voice counts, if I have a real say in what the group does and how it operates, then I'd better think things through carefully and speak wisely. I'm responsible not just for myself but also for my community, so that's a good reason for me to educate myself in the things that matter to my community.

\section{Why Our Standard Approach to Schooling Has Never Worked Well}

Our standard approach to schooling did not arise from scientific research on how children learn, and it certainly did not arise from any research that brought Darwinian evolutionary insights to bear. It came about through an historical process, which I will briefly summarize here (for further detail and documentation, see Gray 2008a).

With the advent of agriculture, children's as well as adults' lives changed dramatically from what they had been in hunter-gatherer times. Agriculture brought landownership, status hierarchies, and, most important for our considerations, servitude and slavery. In these conditions, human willfulness and the spirit of individual autonomy were threats to survival. This cultural change came about much too rapidly for natural selection to play a role. Babies continued to be born, and still are, with all of the instincts for self-determination and self-education that served so well in hunter-gatherer days. To get children to abide by the new rules of unquestioned conformity and obedience, willfulness had to be beaten out of children. Most children spent most of each day at unskilled labor, doing much the same kind of work that they would continue to do for lords and masters in adulthood. This was the state of affairs through the feudal Middle Ages and beyond. The Industrial Revolution did not immediately improve these conditions.
In fact, for a while, it made things worse. Children continued to be treated essentially as slaves, now working in unhealthy, dirty, crowded factories rather than in fields where they at least had experienced fresh air and sunshine.

For a variety of reasons, some religious and some secular, the idea of universal, compulsory education gradually arose and spread, beginning in the seventeenth century in some parts of the world. Education was understood as inculcation in a prescribed curriculum that was deemed essential to the saving of souls, the generation of patriots, or the production of good factory workers. With the rise of schooling, people began to think of learning as children's work, which they must be forced to do. The same power-assertive methods that had been used to make children work in fields and factories were quite naturally transferred to the classroom. Nobody imagined that learning could be play. By this time in history, children's own willfulness, playfulness, and curiosity were commonly seen as works of the devil; surely, those aspects of childhood were worthless for education. The literature of early education is filled with accounts of the duty of schoolmasters to beat children who disobeyed or failed to learn the prescribed lessons. Play was seen as the enemy of education, not the vehicle. The attitude of eighteenth century school authorities toward play is well reflected in John Wesley's rules for Wesleyan schools, which included the statement: "As we have no play days, so neither do we allow any time for play on any day; for he that plays as a child will play as a man" (quoted by Mulhern 1959, p. 383).

As time has moved on, the methods of schooling have become less harsh (at least less corporally harsh), but basic assumptions have not changed. Learning continues to be defined as children's work, and power-assertive means are used to make children do that work. A case can be madeand has been made by Chudacoff (2007) - that the peak of children's freedom in the United States was reached in the early to mid-twentieth century when most children had been freed from long hours of farm or factory work, and school and school-like activities occupied much less of their time than they do today. Over the past 50 or 60 years, schooling and school-like activities (such as organized, agesegregated adult-directed sports) have expanded to take over increasing portions of children's time, leaving less and less opportunity for children to bring their hunter-gatherer instincts to bear in their own education. During that same period, we have seen dramatic increases in childhood anxiety, depression, suicide, obesity, and other mental and physical ailments that can be attributed at least partly to the stress of continuous evaluation by adults and the lack of play (for documentation, see Gray 2010b).

Despite all of this time in school and our culture's extreme emphasis on schooling, the evidence is that 
children do not learn much in school. I, like other college professors, must more or less start from scratch in teaching college courses; I cannot assume that the students remember anything from comparable courses in high school. For example, students spend thousands of hours on math drill in school, and yet, a year or two out, they know little more math than what they would have learned anyway, just in the course of life. Worse, many of them, because of their school experience, have developed such fears of math that they avoid it like the plague (Burns 1998). Our schools do so poorly because they are settings that more or less deliberately deprive children of all of the conditions, described above, that are essential for self-education:

- Children are not free to play, explore, and roam in school. They are instead required to follow a curriculum chosen for them by others and to spend most of the day sitting in their seats.

- Children are strictly segregated by age in school, almost completely deprived of opportunities to interact with older and younger children, from whom they have the most to learn.

- In the classroom, there is typically only one adult, who may or may not be a caring person, and who may or may not be approachable by students seeking help or comfort. Moreover, that adult is often not seen by the children as a full person, but as someone playing a certain role, that of teacher. Models of other professions and interests are completely lacking.

- Children may be exposed, in school, to some of the equipment valued by our culture, but the exposure typically occurs in ways that are controlled by the adults and do not permit the sort of free play that promotes deep and lasting learning.

- Free exchange of ideas is cut off in school, by the prescriptions of the curriculum and by the tests that provide "right" and "wrong" answers to essentially every question.

- Because of the age segregation and the competitive environment and the lack of freedom to leave when one feels harassed, bullying and anxiety are part and parcel of many children's everyday school experience.

- Our standard schools are not, by any stretch of imagination, democratic communities. They are highly stratified top-down structures, with students at the very bottom of the hierarchy.

So, what we do in our schools is to deprive children of all of the conditions that they need to educate themselves, and then we try to teach them something. No wonder the teacher's job is so hard. No wonder our children learn and remember so little of what they are taught. No wonder most children are less happy in school than almost anywhere else (Csikszentmihalyi and Hunter 2003; Herman et al. 2009).
Readers familiar with educational theory know that some of the criticisms of standard schooling presented in this article are similar to criticisms that have long been raised, without any explicit consideration of principles of evolution, by progressive educational theorists-from Rousseau on through Montessori, Dewey, and the modern constructivists (who emphasize Piaget's ideas about child development). It is noteworthy, however, that none of those theorists suggest the degree of departure from standard schooling that is described in this article and represented in practice in hunter-gatherer cultures and Sudbury schools. Progressive educational theories all leave adult educators clearly in charge of children's learning. In schools founded on those theories, teachers attempt to use and direct children's drives to play and explore in ways designed to meet the needs of an established curriculum, chosen by educators, not by children.

The idea that children themselves are motivated to figure out and learn what they need to know to do well in the culture and can successfully direct their own education, if provided with an appropriate environment, is not a component of any of the educational theories discussed in contemporary schools of education (see Gray 2009b; Gray and Chanoff 1984). Moreover, the list of requirements for an educational setting in which children's educative instincts can operate optimally, presented in this article, cannot be found in any previous writings on education. That list comes directly from a comparison of the education-promoting elements of hunter-gatherer bands with those present in a radically alternative modern-day school where children have long educated themselves successfully.

\section{Directions for Further Research}

The appropriately skeptical reader no doubt has many questions concerning the ideas presented in this article, and at least some of those questions provide directions for further research.

The most direct evidence presented in this article for the claim that the hunter-gatherer model of education can work in modern times derives from studies of the Sudbury Valley School and its graduates. But Sudbury Valley is just one relatively small school. Although other Sudbury model schools exist, systematic research at those schools is thus far lacking. Moreover, the students at Sudbury Valley are a self-selected group that, for one reason or another, chose to attend a very unusual school and whose parents agreed to that choice. Some enrolled at an early age because their parents believed in this philosophy of education from the outset, and others came at some point after starting school elsewhere, often because of some problem related to their 
standard schooling, such as repeated failure, persistent rebellion, or general unhappiness (Gray and Chanoff 1986). Although the students seem to me and to the Sudbury Valley staff to encompass the whole normal range of human personality - and they seem to learn well in the school regardless of personality-we presently have no way to prove that. Some students at some point leave the school and return to a traditional public school, and to date there are no systematic data on why they leave. It is possible that the school does not work so well for some as for others, and research aimed at understanding that would be helpful. Hard evidence that the school works for students over the whole normal personality range would increase interest in the school as a general model for contemporary education. On the other hand, evidence that it works well for some but not all students would encourage those who urge more choice in schools, so students could sort themselves out according to their needs.

Aside from further research at Sudbury schools, the analysis presented in this article suggests the need for more studies of children's self-directed play out of school, aimed at understanding how such play leads to acquisition of culturally valued skills, knowledge, and attitudes. A model for such research is the work of Mitra $(2003,2005)$ who documented how thousands of impoverished, often illiterate children in both urban and rural areas of India quickly and efficiently taught themselves how to use a computer, when they had access to one, through their social play and exploration, with no adult guidance at all. Mitra's research has drawn a good deal of attention in the popular press, but so far has not inspired comparable large-scale research by others on children's capacities to educate themselves.

The list of environmental attributes that optimize children's abilities to educate themselves suggests further directions for research. Most glaring, perhaps, is the need for more research on the value of age-mixed interactions among children and adolescents. Today, children are segregated by age more than they ever have been in the past. We not only have age-segregated school classrooms but also age-segregated after-school programs, sports programs, camping experiences, playgroups, and so on. Opportunities for free age-mixed play in neighborhoods have rapidly declined over the last several decades as parents have become increasingly fearful of allowing children to play freely outdoors. The reduced size of nuclear families and reduced significance of extended families (because of their geographical dispersion) have also reduced opportunities for age-mixed play.

Perhaps partly because of such age segregation in the society, very little research has been conducted on children's age-mixed interactions, and almost no research has been conducted on interactions among children or adolescents varying in age by more than two or three years (see
Gray and Feldman 2004). If it is true, as suggested in this article, that age mixing is a key component of children's abilities to learn through their self-initiated activities, then age mixing should move to the forefront of topics for research in developmental psychology and education.

\section{Connections to the EvoS Consortium}

As this special issue of Evolution: Education \& Outreach is dedicated to the EvoS (Evolutionary Studies) Consortium, it seems fitting to end with a note connecting the present article to EvoS. The inspiration for the article came, in part, from the positive reactions to a talk I gave to the EvoS group at Binghamton University in the fall of 2009. EvoS is dedicated to the principle that an evolutionary perspective can inform and improve critical thought and research across the whole range of academic pursuits. The idea that evolutionary thinking can inform thought and research on education is doubly relevant to EvoS as education is not only a topic of study in academia but is also the vehicle by which academia progresses.

I was impressed in my presentation at Binghamton by the playful and inquisitive spirit of those who attended my talk and by the age mixing-among undergraduates, graduate students, and faculty - that occurred during the long dinner and questioning period that followed the talk. Here was a place for free exchange of ideas, where people at various positions on the academic road could learn from and be inspired by one another. In one of his blog posts (found at evostudies.org), David Sloan Wilson (2009) describes well the central role of age mixing in the success of the EvoS program. As Wilson's thoughts make clear, an evolutionary approach is valuable for understanding and improving education across the lifespan.

\section{References}

Bakeman R, Adamson LB, Konner M, Barr R. !Kung infancy: the social context of object exploration. Child Dev. 1990;61:794-809.

Barry H, Child I, Bacon MK. The relation of child training to subsistence economy. Am Anthropol. 1959;61:51-63.

Bock J, Johnson SE. Subsistence ecology and play among the Okavango Delta peoples of Botswana, Hum Nat. 2004;15:63-81.

Burns M. Math: facing an American phobia. Sausalito: Math Solutions Publications; 1998.

Chudacoff HP. Children at play: an American history. New York: New York University Press; 2007.

Csikszentmihalyi M, Hunter J. Happiness in everyday life: the uses of experience sampling. J Happiness Stud. 2003;4:185-99.

DeVore I, Murdock GP, Whiting JWM. Discussions, part VII: Are the hunter-gatherers a cultural type? In: Lee R, DeVore I, editors. Man the hunter. Chicago: Aldine; 1968. p. 335-9.

Draper P. Social and economic constraints on child life among the !Kung. In: Lee R, DeVore I, editors. Kalahari hunter-gatherers: 
studies of the !Kung San and their neighbors. Cambridge: Harvard University Press; 1976. p. 199-217.

Ember C. Feminine task assignment and the social behavior of boys. Ethos. 1973;1:424-39.

Feldman J, Gray P. Some educational benefits of freely chosen age mixing among children and adolescents. Phi Delta Kappan. 1999;80:507-12.

Geary DD. An evolutionarily informed education science. Educ Psychol. 2008;43:179-95.

Gosso Y, Otta E, de Lima M, Morais M, Ribeiro FJL, Bussab VSR. Play in hunter-gatherer societies. In: Pellegrini AD, Smith PK, editors. The nature of play: great apes and humans. New York: Guilford; 2005. p. 213-53.

Gould RA. Yiwara: foragers of the Australian desert. New York: Charles Scribner; 1969.

Gray P. Nature's powerful tutors: the educative functions of free play and exploration. Eye Psi Chi. 2007;12(1):18-21.

Gray P. A brief history of education. Blog at Psychology Today: Freedom to Learn, Aug. 20, 2008. http://www.psychologytoday. $\mathrm{com} / \mathrm{blog} /$ freedom-learn; 2008a.

Gray P. The natural environment for children's education: How the Sudbury Valley School is like a hunter-gatherer band. Blog at Psychology Today: Freedom to Learn, Sept. 3, 2008. http://www. psychologytoday.com/blog/freedom-learn; 2008b.

Gray P. The value of age-mixed play. Education Week, 16 April; 2008c.

Gray P. Play as a foundation for hunter-gatherer social existence. Am J Play. 2009a; $1: 476-522$.

Gray P. Rousseau's errors: They persist today in educational theory. Blog at Psychology Today: Freedom to Learn, Feb. 12, 2009. http://www.psychologytoday.com/blog/freedom-learn; 2009b.

Gray P. Children teach themselves to read. Blog at Psychology Today: Freedom to Learn, Feb. 24, 2010. http://www.psychologytoday. $\mathrm{com} / \mathrm{blog} /$ freedom-learn; 2010a.

Gray P. The dramatic rise in anxiety and depression in children and adolescents: is it connected to the decline in play and rise in schooling? Blog at Psychology Today: Freedom to Learn, Jan. 26, 2010. http://www.psychologytoday.com/blog/freedom-learn; 2010 b.

Gray P. Freedom from bullying: how a school can be a moral community. Blog at Psychology Today: Freedom to Learn, June 8, 2010. http://www.psychologytoday.com/blog/freedom-learn; 2010c.

Gray P. Kids learn math easily when they control their own learning. Blog at Psychology Today: Freedom to Learn, April 15, 2010. http:/www.psychologytoday.com/blog/freedom-learn; 2010d.

Gray P. School bullying: A tragic cost of forced schooling and autocratic school governance. Blog at Psychology Today: Freedom to Learn, May 12, 2010. http://www.psychologytoday. $\mathrm{com} / \mathrm{blog}$ /freedom-learn; 2010e.

Gray P, Chanoff D. When play is learning: a school designed for selfdirected education. Phi Delta Kappan. 1984;65:608-11.

Gray P, Chanoff D. Democratic schooling: what happens to young people who have charge of their own education? Am J Educ. 1986;94:182-213.

Gray P, Feldman J. Patterns of age mixing and gender mixing among children and adolescents at an ungraded democratic school. Merrill Palmer Q. 1997;43:67-86.
Gray P, Feldman J. Playing in the zone of proximal development: qualities of self-directed age mixing between adolescents and young children at a democratic school. Am J Educ. 2004;110:108-45.

Greenberg D, Sadofsky M. Legacy of trust: life after the Sudbury Valley School experience. Framingham: Sudbury Valley School Press; 1992.

Greenberg D, Sadofsky M, Lempka J. The pursuit of happiness: the lives of Sudbury Valley alumni. Framingham: Sudbury Valley School Press; 2005.

Groos K. The play of animals. New York: Appleton; 1898.

Groos K. The play of man. New York: Appleton; 1901.

Guemple L. Teaching social relations to Inuit children. In: Ingold T, Riches D, Woodburn J, editors. Hunters and gatherers 2: property, power, and ideology. Oxford: Berg; 1988. p. 130-49.

Herman KC, Reinke W, Traylor PJ, KB AG. Childhood depression: rethinking the role of school. Psychol Sch. 2009;46:433-46.

Ingold $\mathrm{T}$. On the social relations of the hunter-gatherer band. In: Lee RB, Daly R, editors. The Cambridge encyclopedia of hunters and gatherers. Cambridge: Cambridge University Press; 1999. p. 399-410.

Blurton Jones N, Hawkes K, Draper P. Differences between Hazda and !Kung children's work: original affluence or practical reason? In: Burch Jr ES, Ellanna LJ, editors. Key issues in hunter-gatherer research. Oxford: Berg; 1994. p. 189-215.

Kelly RL. The foraging spectrum: Diversity in hunter-gatherer lifeways. Washington: Smithsonian Institution Press; 1995.

Kirschner DH. Producing unshoolers: learning through living in a U.S. education movement. Doctoral dissertation, Department of Anthropology, University of Pennsylvania; 2008.

Lee RB. Reflections on primitive communism. In: Ingold T, Riches D, Woodburn J, editors. Hunters and gatherers 1. Oxford: Berg; 1988. p. 252-68.

Lee RB, DeVore I. Problems in the study of hunters and gatherers. In: Lee RB, Lee I, editors. Man the hunter. Chicago: Aldine; 1968. p. $3-12$.

Liedloff J. The continuum concept, revised edition. New York: Knopf; 1977.

Mitra S. Minimally invasive education: a progress report on the "holein-the-wall" experiments. Br J Educ Technol. 2003;34:367-71.

Mitra S. Self-organizing systems for mass computer literacy: findings from the 'hole in the wall' experiments. Int $\mathrm{J}$ Dev Issues. $2005 ; 4: 71-81$.

Mulhern J. A history of education: a social interpretation. 2nd ed. New York: Ronald Press; 1959.

Power TG. Play and exploration in children and animals. Mahwah: Erlbaum; 2000.

Sahlins M. Stone age economics. Chicago: Aldine; 1972.

Sudbury Valley School. The crisis in American education: an analysis and a proposal. Framingham: Sudbury Valley School Press; 1970.

Thomas EM. The old way. New York: Farrar, Straus \& Giroux; 2006.

Turnbull CM. The ritualization of potential conflict between the sexes among the Mbuti. In: Leacock EB, Lee RB, editors. Politics and history in band societies. Cambridge: Cambridge University Press; 1982. p. 133-55.

Wilson DS. On the importance of mixed-age learning and how to make the most of it in an EvoS program. EvoS Blog at http:// evostudies.org/blog/?p=107; 2009. 